\title{
Performance Analysis of Submerged Vehicle Electric Propulsion with DC Motor 2x1850 kW 380 Volt which Supplied Power 10260 AH on 190 VDC in Series and Parallel Circuits
}

\author{
Indra Ranu Kusuma ${ }^{1}$, Sardono Sarwito ${ }^{2}$, Annisa Maya Shabrina ${ }^{3}$ \\ (Received: 23 January 2017 / Revised: 24 June 2019 / Accepted: 02 July 2019)
}

\begin{abstract}
DC motor that is used as a main propulsion, typically used on ships with high maneuverability, special ships, ships wtih great cargo load, and the ships that use prime movers non-reversible (generally using a gas turbine, steam turbine and high-speed diesel in its use is unlikely to reverse its rotation quickly). As for the expected results we will obtain the characteristics (such as torque and rotation) on a series DC motor series and in parallel on the propulsion system, determines where an efficient circuit for the propulsion system, getting long use of batteries used for such needs. In this research will be assessed numerically by simulation using MATLAB-Simulink the drive system by using a DC motor in a vehicle submerged was carried out together series and parallel. The result obtained is the same input voltage of 190 Volt same torque value of $140 \mathrm{Nm}$ is generated at the motor circuit series and parallel. So that a series circuit, generating a service speed of 12 knots and 21.5 knots using a converter, and usually when submerged condition in the sea. For parallel circuit produces speed of 14 knots and 11 knots using a converter.
\end{abstract}

Keywords—DC motor, matlab-simulink, propulsion system, torque

\section{INTRODUCTION}

$\mathrm{T}_{\mathrm{b}}$ he electrical propulsion system is systems on ships using electrical machines AC or DC the performance of the main engine, which in this case the generator is connected to a switchboard, and further energy or electric current is passed to the transformer, then converted using konventer to electric motors which drive the ship's propeller. In general, the ship that has special utility that uses a DC motor and for profit-oriented commercial ships generally use AC motors.

DC electric motor that is used as a main propulsion, typically used on ships with high maneuverability, special ships, ships with great cargo load, and the ships that use prime movers non-reversible (generally using a gas turbine, steam turbine and high-speed diesel in its use is unlikely to reverse its rotation quickly). The development of a prime mover for main propulsion on board experienced rapid growth since the invention of the steam by J. Watt, by Rudolf Diesel diesel engines and gas turbines by Brayton. Things that need to be considered in the use of a DC motor as the actuator is

Indra Ranu Kusuma, Department of Marine Engineering, Institut Teknologi Sepuluh Nopember, Surabaya 60111, Indonesia, Email : Irkusuma93@gmail.com

Sardono Sarwito, Department of Marine Engineering, Institut Teknologi Sepuluh Nopember, Surabaya 60111, Indonesia, Email : sarsar@its.ac.id

Annisa Maya Shabrina, Department of Marine Engineering, Institut Teknologi Sepuluh Nopember, Surabaya 60111, Indonesia, Email : annisamayas.ams@gmail.com matters related to electric motors, among others, the initial flow, the speed setting method, the method of reversal rotation, braking and others. In the early years of the discoveries about the three prime movers only revolve around the improvement of the working system. For example, icebreaker (ice breaker) uses a DC motor in this case due to the required torque very large propeller.

There are three ways to regulate rotation in a DC motor including a magnetic flux arrangements, armature resistance arrangement, as well as the terminal voltage regulation [1].

As for the expected results we will getting characteristics (such as torque and rotation) on a DC series motor and in parallel on the propulsion system, determines where an efficient circuit for the propulsion system, the long usage of batteries used for such needs.

Things that need to be considered in the use of DC motor as the actuator is matters related to electric motors, among others, the starting current, the speed setting method, reversal method rounds, etc. There are three kinds of methods to regulate the rotation of the DC motor, one of which is to control the terminal voltage. In the electric propulsion system, it takes some variation of the circuit to match needs with rotation speed generated by DC motor [1].

The most advanced vehicles submerged make their own fresh water from sea water. There is also a reserve of air to the process of liberating oxygen from freshwater. Although the vehicle submerged float with ease, the ship was able to dive to the ocean floor and remained there until months long. The secret lies in the double wall construction typical of the ship. Special spaces watertight (or ballast tank) between the outer wall and inner wall can be filled with sea water thereby increasing the overall weight and reduced buoyancy. 
Resistance are the forces that hinder the pace of the ship. These resistance include:

a. The force perpendicular to the hull (the normal force)

b. The force tangent to the hull.

In designing a new ship, the very thing that influenced the design of the vessel:

a. buoyancy

b. Stability

Total Resistance submerged vehicle can be formulated as follows:

$\mathrm{R}_{\mathrm{T}}=\mathrm{R}_{\mathrm{BH}}+\mathrm{R}_{\mathrm{APP}}$

Where $R_{T}$ is the total resistance of ship, $R_{B H}$ is the hull resistance and $R_{A P P}$ is the additional resistance (such as contol surfaces, the condition of shipping)

While to calculate $\mathrm{R}_{\mathrm{BH}}$, the formula is presented on equation (2)

$\mathrm{R}_{\mathrm{BH}}=1 / 2 \rho A V^{2} \mathrm{C}_{\mathrm{T}}$

Where, $\rho$ is density of sea water, A is the large of areas can use formula $\mathrm{L}^{2}, \mathrm{~V}$ is the speed service of ship. Equation (3) present the formula to calculate the coefficient of total ship resistances.

$\mathrm{C}_{\mathrm{T}}=\mathrm{Cf}+\Delta \mathrm{Cf}+\mathrm{Cr}+\mathrm{Cw}$

$$
\mathrm{Cf}=\frac{0,075}{(\log R e-2)^{2}}
$$

$\operatorname{Re}=\frac{V x L}{v}$

$$
\Delta \mathrm{Cf}=\text { between } 0,0004-0,0009
$$

The advantage in the use of electric propulsion systems when compared with other propulsion systems is the initial investment that is not too big, save space, lighter and less loss of power in the transitional system compared to other propulsion systems. Electrical connections between generators and propulsion motors more flexibility in laying equipment in the room. Moreover, it can use a variety of prime movers such as diesel, gas turbines, steam turbines, and its output can be more easily incorporated than the mechanical system. For the type of prime movers indirectly, electric drive has the advantage could reverse rotation propeller with relatively easy control.

The disadvantage of the electric propulsion system, namely in terms of the sound or noise of the ship, it is the absence of explosion or combustion in the electric motor, the motor propulsion system is not too intrusive in terms of sound. In addition, efficient electric propulsion system only at maximum power, when compared to diesel engines. Require extra caring, larger and more expensive, not suitable for high speed applications and is not suitable for large power applications.

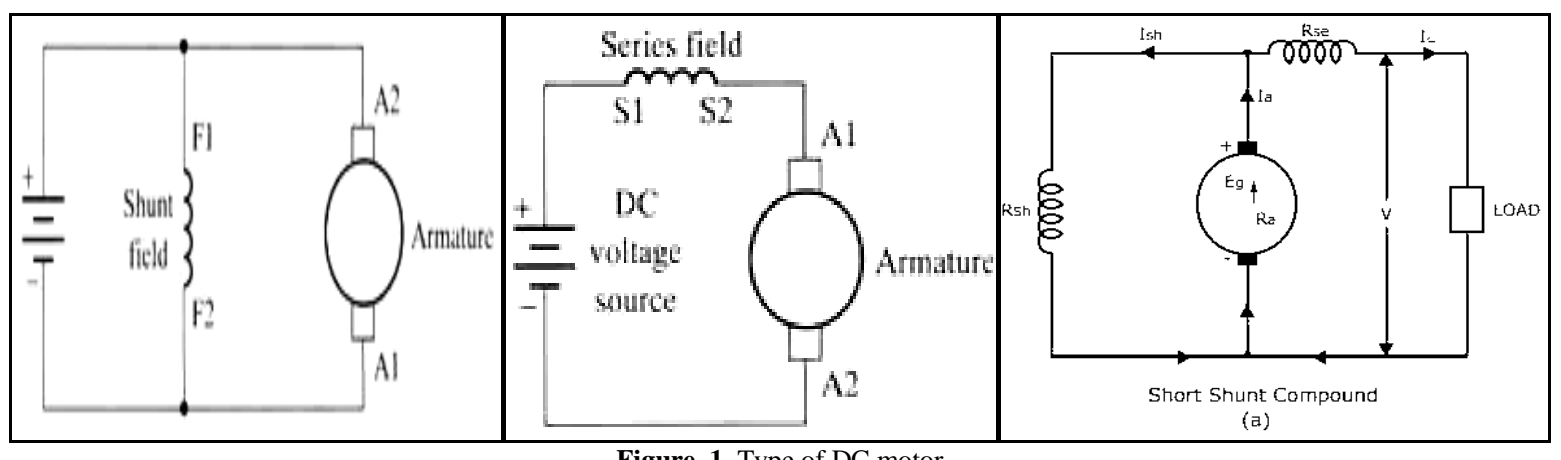

Figure. 1. Type of DC motor

The electric motor is an electromechanical device that converts electrical energy into mechanical energy. This mechanical energy is used for, for example, rotate the pump impeller, fan or blower, drive the compressor, lifting materials, and sebagaianya. DC motors are motors that require a supply voltage in the same direction on the field coils and coil anchor to be converted into mechanical energy. Field coil in the dc motor called the stator (the part that does not rotate) and the anchor coil called a rotor (rotating part).

Figure 1 is a picture of the series of DC motors. Type of DC motor based on connection: series, shunt, and compund.

DC motor control to regulate the terminal voltage using Ward-Leonard. This type of arrangement is commonly used in the industry which has rolling (rolling process) such as, paper industry, industrial steel plates, etc. With some modifications, this method can be applied in particular to the ship electric propulsion system on board. Ward-Leonard system is more than just a simple way to implement a variable $\mathrm{dc}$ to $\mathrm{dc}$ armature of the motor. It really can force the motor separately develop torque and speed required by the load.

DC power system usually consists of several rounds of high or medium generators that are arranged in parallel. Selection of the size of the engine based on the operating level that allows multiple operating units does not exceed the total power generated. To obtain optimum power, generators usually have a generator at two different rounds. The resulting electrical current generator is connected to the main terminal through the connecting circuit. This interface circuit is intended to connect and memutuskaan flows in the event of over-load and shortcircuit. Often a circuit terminal system created to meet the power requirements on a vessel taken at the same terminal through a transformer or a motor generator.

To reverse the direction of rotation of DC motors are usually done on a fixed pitch propeller type, there are two approaches that might be used. The first is to reverse the direction of current flow in the motor field. The second method is to change the direction of the current anchor. DC electric drive systems are often fitted with a 
(pISSN: 2541-5972, eISSN: 2548-1479)

field shunt regulator that keeps the motor operating at constant power. Mechanically described as setting reduction gear ratio allowing the main engine to operate at engine speed changing. On large ships torque power an estimated $70 \%$ of propeller rotation rpm [2-8].

MATLAB (Matrix Laboratory) is a program for analysis and numerical computation and an advanced mathematical programming language built on the premise that using the nature and form of a matrix.

Initially, the program is an interface for collection of numerical routines of LINPACK and EISPACK project, and developed using the FORTRAN language but is now a commercial product of the company Mathworks, Inc.yang in the subsequent development was developed using $\mathrm{C}++$ and assembler language (primarily tofunction MATLAB basic functions).

MATLAB has evolved into a sophisticated programming environment that contains functions builtin to perform the task of signal processing, linear algebra and other mathematical calculations. MATLAB also contain additional toolbox that contains the functions for specific applications.

MATLAB is extensible, meaning that a user can write new functions to be added to the library when those functions built-in available unable to perform certain tasks. Programming skills required is not too difficult if you have had experience in other programming languages such as C, Pascal, or FORTRAN

\section{METHOD}

In this research is used methodology to determine the purpose and the result. This research uses some methods. These following methods are: (1) Identification and Problem Formulation (2) Identification (3) Analyzing and Interpretation Data (4) Result.

A. Formulation of the problem

The first stages is to identify existing problems and then will look for solutions in this research.

B. Study Literature

Study Literature is a second step to do this research to looking for many references and analysis material. Those are shall accordance by confidence literature then help to do this research. Study Literature can take from sourch of references such as Book, Catalog, Journals, Papers, etc.

\section{Data Collection}

Data - the necessary data will be collected through a variety of ways, including the following:

$\square$ Primary data: primary data obtained from the variation rangakain DC motor on the circuit electrical propulsion system in previous research.

Data Secondary: secondary data obtained from relevant journals, papers, books and the internet.

\section{Systems Planning and Analysis}

At this step of planning will be done analysis of any variations in the sequence of DC motors will be used for ship propulsion drive system, consisting of:

- Analysis of variations of the DC motor circuit

- Analysis on each circuit power requirement DC motors

- Analysis of the needs of current or amperage in each set of DC motors

- Analysis battery voltage generated at each circuit DC motors

At this step Matlab-Simulink software is used to convert from the motor circuit matlab series

E. Conclusion and Recommendation

Conclusion and recommendation made based all aspect of this research discussion.

\section{RESULTS AND DISCUSSION}

\section{A. Principal Dimension}

Table 1 shows the principal dimension of the ship. This data will be used for calculation.

\section{B. Data of Propulsion System}

In this research only the electric motor and batteries that will be discussed. Here is more information about batteries and electric motors used in these systems.

a. Electric motor

- Quantity : 1 piece

- Type : DL $380 \mathrm{~V}$ shunt motor, DC

- Power: 2 x $1850 \mathrm{~kW}$ at $200 \mathrm{rpm}$ propeller rotation

- Construction: made double field

The main task of a DC electric motor is to move the ship (forward / backward) through an intermediaryflexible coupling (flexible coupling) to the propeller or propeller. Electric current obtained from the four batteries or obtained directly from the four diesel generators. Motor made double anchor that can be assembled series or in parallel when used depending on the desired stimulation based regime.

b. Battery

The specifications of the batteries used in the vehicleunders are:

- Total: 480 cell, divided 4 groups (Groups I and II, R. Batt. 1 and Group III and IV in R. Batt. 2)

- Voltage: 2-3 volt / cell

- Capacity: $10260 \mathrm{AH}(27.5 \mathrm{kWh})$

- Dimensions: (1421 x 290 x 450) mm

- Weight: $525 \pm 2 \mathrm{~kg}$

Placement of the battery is divided into 4 groups, each group was placed in a row 6 rows. Each line consists of 20 cells. Figure 2 is show of scheme of DC Motor in series circuit and paralel circuit.

TABLE 1.

THE PRINCIPAL DIMENSION OF SHIP

\begin{tabular}{|c|c|}
\hline \multicolumn{2}{|c|}{ THE PRINCIPAL DIMENSION OF SHIP } \\
\hline $\mathrm{LOA}$ & $59.570 \mathrm{~m}$ \\
\hline Load Length Press & $45.159 \mathrm{~m}$ \\
\hline Inner Diameter & $6.2 \mathrm{~m}$ \\
\hline Draft & $5.5 \mathrm{~m}$ \\
\hline Diving Displacement & $1390 \mathrm{~m}^{3}$ \\
\hline Diving Depth & $250 \mathrm{~m}$ \\
\hline Dive time speed & $21.5 \mathrm{knot}$ \\
\hline Shipping distance & 22 NM (80\% Batt) \\
\hline
\end{tabular}



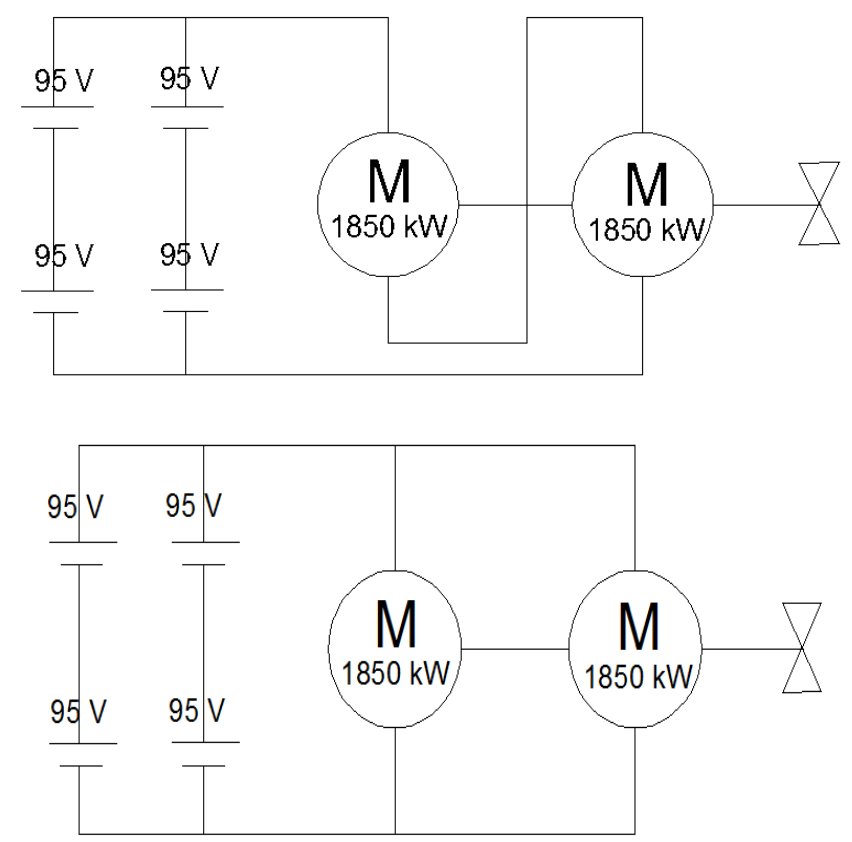

Figure. 2. DC Motor circuit scheme for ship propulsion

TABLE 2.

THE PRINCIPAL DIMENSION OF SHIP

\begin{tabular}{ll}
\multicolumn{1}{c}{ THE PRINCIPAL DIMENSION OF SHIP } \\
\hline Hull form & $\mathrm{C}_{\mathrm{r}} \times 10^{-3}$ \\
Deep Quest & 0.677 \\
DSRV & 0.435 \\
Fleet Submarine & 0.39 \\
Albacore & 0.1 \\
\hline
\end{tabular}

\section{Detail Calculation}

From the above data it can be calculated that resistance also influenced by the speed generated by a submerged vehicle. The following is the calculation of total resistance:

1. Calculation of the Reynolds number

Here is a calculation to find the Reynolds number:

$\mathrm{Re}=(\mathrm{V} \times \mathrm{L}) / \mathrm{v}$

$$
=172.863248
$$

2. Calculation of $\mathrm{Cf}$

$$
\mathrm{Cf}=0.075 /(\log \mathrm{Re}-2)^{2}
$$$$
=0.06198
$$

3. Determining the value of correlative allowance $(\Delta \mathrm{Cf})$

$\Delta \mathrm{Cf}$ has a value of 0.0004 to 0.0009

So from the above statement is 0.0004

4. Residu Resistance determine $(\mathrm{Cr})$

According to the table 2, taken value of $0.39 \times 10-3$ ie submarine fleet, then the Taken value of $0.39 \mathrm{x}$ 10-3 ie submarine fleet, then the value of $\mathrm{Cr}$ is 0.00039 and albacore $0.1 \times 10-3$

5. Determining the value detainee Wave

Due to its value is very small and depends on the desaigner then its value is ignored so 0

6. Calculating nondimentional drag coefisin

$$
\mathrm{Ct}=\mathrm{Cf}+\mathrm{Cw}+\Delta \mathrm{Cf}+\mathrm{Cr}
$$

$$
=0.06248
$$

7. Calculating the value of Prisoners bare Hull

$$
\begin{aligned}
\mathrm{RBH} & =1 / 2 \rho \mathrm{AV}^{2} \mathrm{Ct} \\
& =101,730.1444 \mathrm{~N} \\
& =101.7301444 \mathrm{kN}
\end{aligned}
$$

8. Calculating the value of additional prisoners (RAPP) Additional resistance value formula is the same as the $\mathrm{RBH}$ only distinguishing is the value $\mathrm{Ct}$. For $\mathrm{Ct}$ at RAPP based on this Table 3

$$
\begin{aligned}
& \text { So, } \mathrm{Ct}=0,005 \\
& \text { So, } \begin{aligned}
\mathrm{R}_{\mathrm{APP}}= & 1 / 2 \rho \mathrm{AV}^{2} \mathrm{Ct} \\
& =34190,37061 \mathrm{~N} \\
& =34,19037061 \mathrm{kN}
\end{aligned}
\end{aligned}
$$

9. Calcukating Total Resistance $\left(\mathrm{R}_{\mathrm{T}}\right)$

$$
\begin{aligned}
\mathrm{R}_{\mathrm{T}} & =\mathrm{R}_{\mathrm{BH}}+\mathrm{R}_{\mathrm{APP}} \\
& =101,7301444+34,19037061 \\
& =135,9205 \mathrm{kN}
\end{aligned}
$$

D. Calculation of Torque

1. Looking for EHP

$$
\mathrm{EHP}=\text { Rtdinas } \mathrm{x} \mathrm{V}
$$

$$
\begin{aligned}
& =135,9205 \times 21,5 \\
& =2922,29 \mathrm{~kW} \\
& =3973.203 \mathrm{HP}
\end{aligned}
$$

2. Looking for DHP

Is the power absorbed by the propeller of perporosan system or power delivered by the system perporosan to the propeller to be converted into thrust (thrust)

$\mathrm{DHP}=\mathrm{EHP} / \mathrm{Pc}$

Where, $\mathrm{Pc}=\eta \mathrm{H} \times \eta \mathrm{rr} \times \eta \mathrm{o}$

- Hull Efficiency $(\eta \mathrm{H})(1-\mathrm{t}) /(1-\mathrm{w})$

Wake friction or join current is the ratio between the speed of the ship with the speed of the water leading to the propeller. Using the formula given by Taylor, then obtained:

$$
\begin{aligned}
\mathrm{W} & =0.5 \mathrm{Cb}-12: 05 \\
& =0.4070
\end{aligned}
$$

Values $\mathrm{t}$ can be sought from the value $\mathrm{w}$ is already known, namely:

$\mathrm{t}=\mathrm{k} . \mathrm{w}$ 
International Journal of Marine Engineering Innovation and Research, Vol. 4(1), Jun. 2019. 1-10

(pISSN: 2541-5972, eISSN: 2548-1479)

$$
=0.285
$$

So $\eta \mathrm{H}=(1-\mathrm{t}) /(1-\mathrm{w})=1,205$

- value $\eta \mathrm{R}$ for vessels with propeller-type single screw ranged from 1.0 to 1.1 then the value 1

- Efficiency Propulsion ( efficiency that is efficiency of the propeller at the time of open water test. Its value is between 40-70\%, and taken: $40 \%$

- $\mathrm{Pc}=\eta \mathrm{H} \times \eta \mathrm{rr} \times \eta \mathrm{O}=0,4824$
$\mathrm{DHP}=\mathrm{EHP} / \mathrm{Pc}$

$$
=2922,29 \mathrm{~kW}
$$

3. Looking for Torque $\mathrm{DHP}=\frac{2 x 3,14 x n x Q}{60}$

From above formula $\mathrm{Q}=\frac{D H P x 60}{2 x^{3}, 14 x n}(\mathrm{ft} \mathrm{lb})$ $\mathrm{Q}=102,37 \mathrm{ft} \mathrm{lb}=139,599 \mathrm{Nm}$

TABLE 3.

\begin{tabular}{|c|c|c|c|}
\hline Appendage & & Area Basis & $\mathbf{C}_{\mathrm{t}}$ \\
\hline Small domes & & profile & 0.015 \\
\hline Antennae & & Projected & 1.2 \\
\hline Cylinders & & Projected & 1.2 \\
\hline Arms & & Wetted surface & 0.005 \\
\hline $\begin{array}{l}\text { Long } \\
\text { protuberances }\end{array}$ & faired & Wetted surface & 0.005 \\
\hline Holes in skin & & Projected frontal & 0.5 \\
\hline Planes & & Projected frontal & 0.011 \\
\hline
\end{tabular}

THE VALUE OF CT

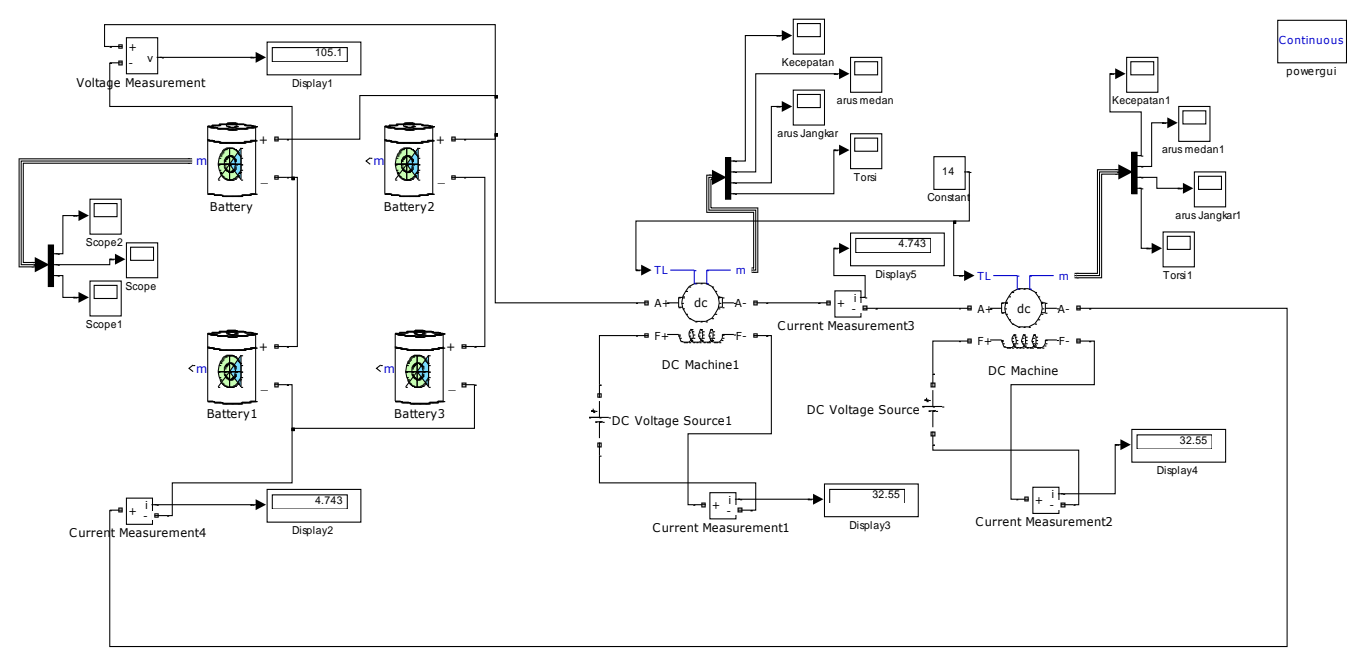

Figure. 3. Series circuit in Matlab-simulink

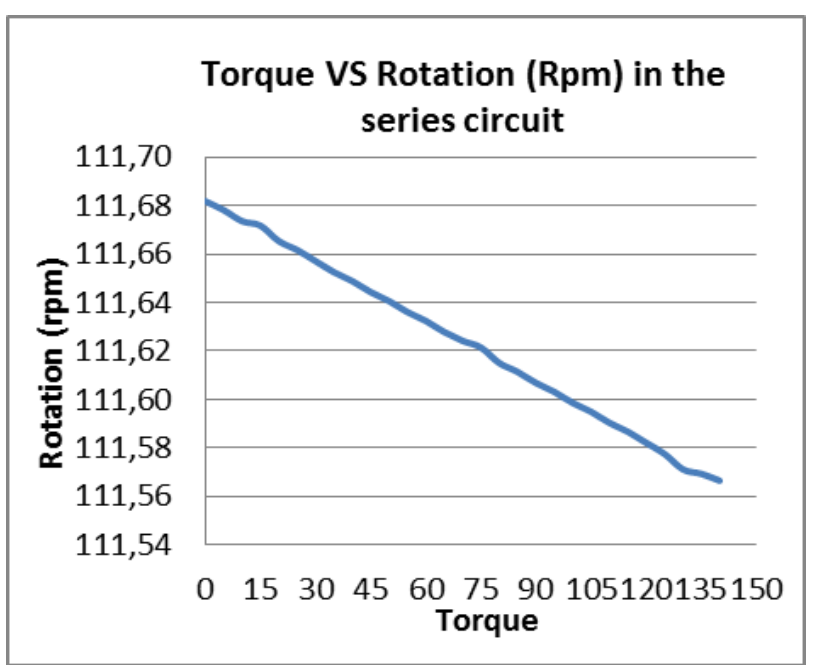

Figure. 4. Graphic of the relation between torque and rpm at the series circuit 


\section{Speed VS Rotation in Series Circuit}

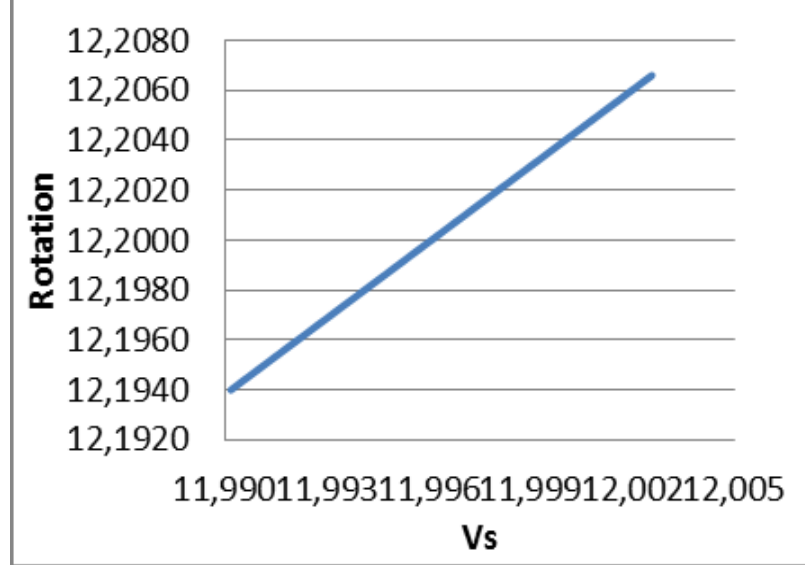

Figure. 5. Graphic of the relationship between Rotatiom and Speed in series circuit

From the figure 3 circuit DC motor series using Matlab-Simulink, there is scope in the form of graphs. The simulation was performed within 5 seconds. There is some data to be inputted, among others, a large voltage on each battery, In this circuit, the voltage generated by the series circuit in a battery of $190 \mathrm{~V}$ with AH 10260. After a series of simulated results obtained graphs among others: chast current field, the current armature, speed and torque.

After running for 5 seconds on matlab-simulink it will automatically generate a graph. Scope of circuit, taken data is constant and input the data in the table observations, repeat until all the variations do. In this trial insert torque variation of $0-140$. However, the variation can simply enter the numbers $0-14$ with a difference of 0.5 so that tertlis the torque variation is 0 or 0.5 or 1 or 1.5 or 2 or 2.5 , and so on until the 14 variations.

Enter the observational data in the table 1, so make chart from these tabel with variation torque-rotation, Rotation and speed, performance.
Figure 4 shows the relationship rotation (RPM) and torque in a series circuit. Based on the graph, the torque value is directly proportional to the value of rotation (rpm). When torque is 0 then the value of $\mathrm{rad} / \mathrm{s}$ at 111.68. When the value of maximum torque, it is precisely the value of rad / $\mathrm{s}$ was only 111.57 for the full usage of $100 \%$. This means that the torque value is inversely proportional to the value of rotation (rpm).

Figure 5 shows the relationship between rotation ( $\mathrm{rad}$ / s) and Vs (Knot) in the series circuit. Based on the graph, the value of rotation ( $\mathrm{rad} / \mathrm{s})$ is proportional to the value of Vs (knots). As at the time of his round 12.2066 $\mathrm{rad} / \mathrm{s}$ speed indicates the number 12.003 knots and this is the maximum value of the series circuit. Meanwhile, when the current value of the rotation is $12.2 \mathrm{rad} / \mathrm{s}$ the value of his service speed was 11.996 knots and it is the middle value of the graph above. As for the minimum value is the current value of the rotation is $12.194 \mathrm{rad} / \mathrm{s}$ and the velocity value is 11.990 knots. It is enough to prove that the rotation speed and proportional.

\section{Torque VS Rotation in paralel circuits}

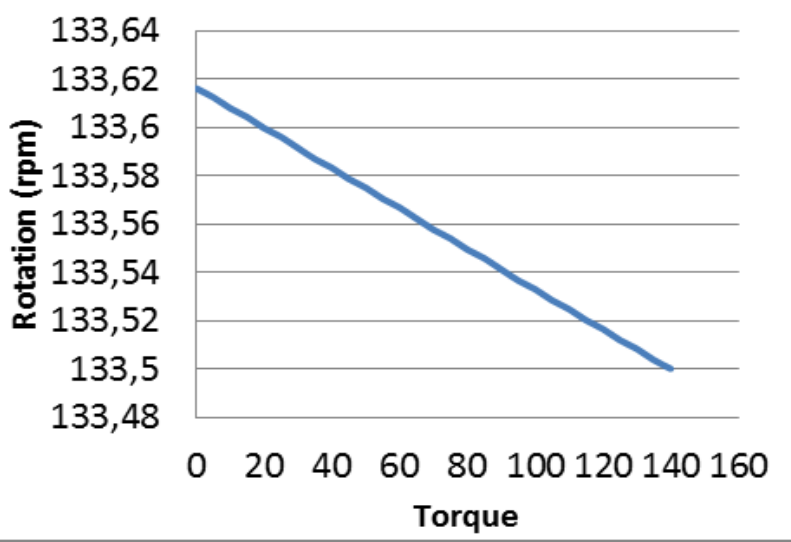

Figure. 6. Graphic of the relationship between torque and rotation in parallel circuit 


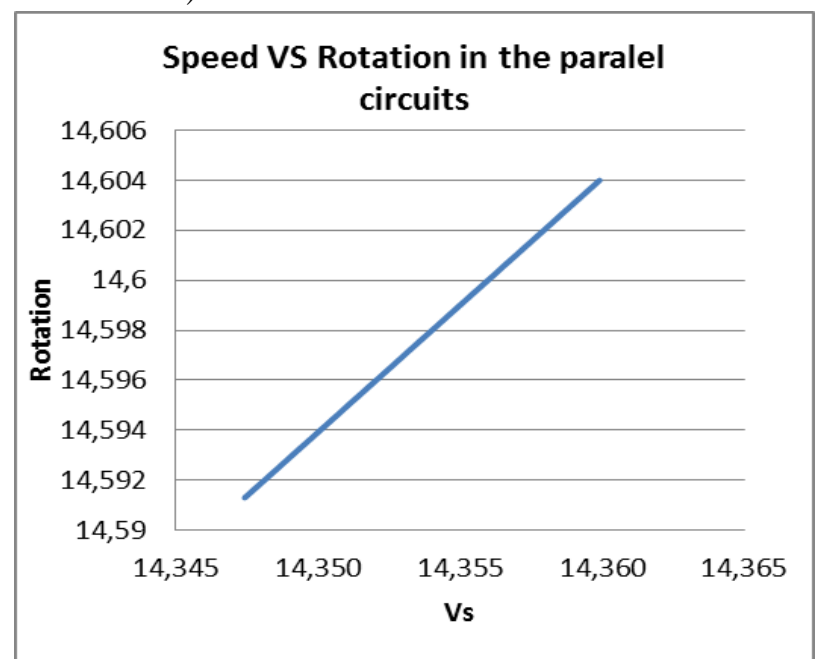

Figure. 7. Relation between Rotatiom and speed

Figure 6 show the graph of the relationship between torque and rotation torque $(\mathbf{r p m})$ in a parallel circuit. Based on the graph, the torque value is inversely proportional to the value of rotation (rpm). When torque is 0 then the value of $133.62 \mathrm{rpm}$. When torque 50 putarannnya value of $133.56 \mathrm{rpm}$. When the maximum torque value of 140 , it was only $133.5 \mathrm{rpm}$ value for the use of the full $100 \%$. This means that the torque value is inversely proportional to the value of rotation ( $\mathrm{rpm})$. When the torque value is small then big and reverse rotation torque value greater then rotation a great value.

Figure 7 show the relationship between rotation $(\mathrm{rad} /$ s) and Vs (Knot) in a parallel circuit. Based on the graph, the value of rotation $(\mathrm{rad} / \mathrm{s})$ is proportional to the value of Vs (knots). As at the time of his round $14.604 \mathrm{rad} / \mathrm{s}$ speed indicates the number 14.360 knots and this is the maximum value of the parallel circuit. Meanwhile, when the current value of rotation $14.5976 \mathrm{rad} / \mathrm{s}$ the value of his service speed was 14.354 knots and it is the middle value of the graph above. As for the minimum value is the current value of rotation $14.5916 \mathrm{rad} / \mathrm{s}$ and the velocity value is 14.347 knots. It is enough to prove that the rotation speed and proportional.

E. Calculation of eficiency

To calculate the efficiency, it is necessary to use the calculation as follows:

a. Determining the value of the current armature

Ia was on the the motor taken there on the motor or the scope of measurement data on circuit in matlab. Valued of Ia : $38.2477 \mathrm{~A}$

b. Determining the value of the current field

If the motor taken there on the motor or the scope of measurement data on circuit in matlab. If the value: $3.255 \mathrm{~A}$ c. Determining the value of current flowing source (IL)

$$
\begin{aligned}
\mathrm{IL} & =\mathrm{Ia}+\mathrm{If} \\
& =38.2477+3.255 \\
& =41.5027 \mathrm{~A}
\end{aligned}
$$

d. Determining the value of the input power (Pin)

Pin $=$ Vt $x$ IL

$$
\begin{aligned}
& =190 \times 41.5027 \\
& =7885.513 \text { watts }
\end{aligned}
$$

e. Determining the value of Prisoners anchor ( $\mathrm{Ra}$ ) Armature resistance value is the value of resistance on the motor and this is contained in the machine parameters in the DC block and the value was $0.06727 \mathrm{ohm}$

f. Determining the value detainee field ( $\mathrm{Rf})$

The resistance field value is the value of resistance on the motor and this is contained in the machine parameters in the DC block and the value was 30.72 ohms

g. Determining the value of loss of copper (WCU)

$\mathrm{WCU}=\left(\mathrm{Ia}^{2} \mathrm{Ra}\right)+\left(\mathrm{If}^{2} \mathrm{Rf}\right)$

$$
\begin{aligned}
& =(38.24772 \times 0.06727)+(3.2552 \times 30.72) \\
& =423.8875 \text { watt }
\end{aligned}
$$

h. Determining the value of iron loss and mechanical $\mathrm{W}(\mathrm{b}+\mathrm{m})=20 \% \mathrm{WCU}$

$$
=84.777 \text { watts }
$$

i. Determining the value of total loss (Wtot)

$$
\begin{aligned}
\text { Wtot } & =\mathrm{Wcu}+\mathrm{W}(\mathrm{b}+\mathrm{m}) \\
& =423.8875+84.777 \\
& =508.6651 \text { watt }
\end{aligned}
$$

j. Determining the value of the output power (Pout)

$$
\begin{aligned}
\text { Pout } & =\text { Pin }- \text { Wtot } \\
& =7885.513-508.6651 \\
& =7376.848 \text { watt }
\end{aligned}
$$

k. Determining the value of efficiency $(\eta)$

$$
\begin{aligned}
\text { Eff } & =\text { Pout } / \text { Pin } \times 100 \% \\
& =7376.848 / 7885.513 \times 100 \% \\
& =93.5493 \%
\end{aligned}
$$




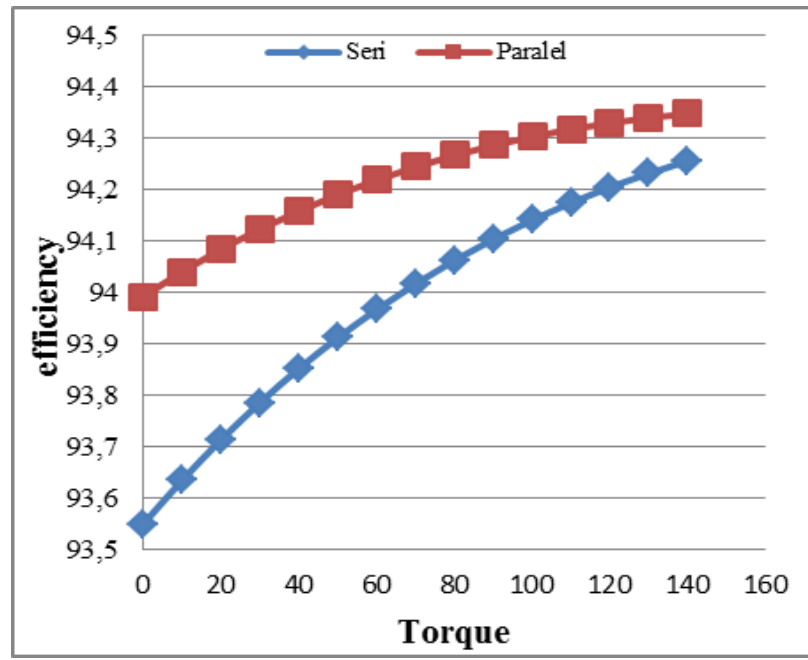

Figure. 8. comparison between eficiency and torque

From Figure 8 . In the graph above can be seen that the efficiency of circuit, the relationship is directly proportional to the torque, if the torque higher the value the higher the efficiency. The maximum value on the graph above is if torque is 140 then the efficiency is $94.3 \%$ but with a torque value of 0 to a parallel circuit still has a value of an efficiency of $93.99 \%$.
As for the series circuit is if torque is 140 then the efficiency is $94.2 \%$ but with a torque value of 0 to a series circuit still has value at $93.5 \%$ efficiency. For the price of efficiency in both circuit comparison and the higher parallel circuits.

TABLE 4.

SIMULATION RESULT OF SERIES CIRCUITS WHEN USAGE ON $10 \%$

\begin{tabular}{|c|c|c|c|c|c|c|c|c|c|c|}
\hline Q Motor & Torque & $\mathrm{rad} / \mathrm{s}$ & RPM & RPS & THP & SHP & BHP & Va & Vs $(\mathbf{m} / \mathbf{s})$ & Vs (knot) \\
\hline 26,788 & 0 & 10,7854 & 98,6788 & 1,6446 & 0 & 0 & 0 & 3,2367 & 5,4581 & 10,6051 \\
\hline 27,703 & 10 & 10,7844 & 98,6697 & 1,6445 & 677,26032 & 691,08196 & 813,0376 & 3,2364 & 5,4576 & 10,6041 \\
\hline 28,589 & 20 & 10,7835 & 98,6614 & 1,6444 & 1354,4076 & 1382,0486 & 1625,9395 & 3,2361 & 5,4572 & 10,6033 \\
\hline 29,839 & 30 & 10,7826 & 98,6532 & 1,6442 & 2031,44184 & 2072,8998 & 2438,7057 & 3,2358 & 5,4567 & 10,6024 \\
\hline 30,682 & 40 & 10,7818 & 98,6459 & 1,6441 & $2708,38811.6$ & 2763,6614 & 3251,3663 & 3,2356 & 5,4563 & 10,6016 \\
\hline 31,659 & 50 & 10,7808 & 98,6367 & 1,6439 & 3385,1712 & 3454,2563 & 4063,831 & 3,2353 & 5,4558 & 10,6006 \\
\hline 32,546 & 60 & 10,7799 & 98,6285 & 1,6438 & 4061,86632 & 4144,7616 & 4876,1901 & 3,2350 & 5,4553 & 10,5997 \\
\hline 33,494 & 70 & 10,7790 & 98,6203 & 1,6437 & 4738,4484 & 4835,1514 & 5688,4134 & 3,2347 & 5,4549 & 10,5988 \\
\hline 34,366 & 80 & 10,7781 & 98,6120 & 1,6435 & 5414,91744 & 5525,426 & 6500,5011 & 3,2345 & 5,4544 & 10,5979 \\
\hline 35,276 & 90 & 10,7772 & 98,6038 & 1,6434 & 6091,27344 & 6215,5851 & 7312,4531 & 3,2342 & 5,4540 & 10,5971 \\
\hline 36,185 & 100 & 10,7763 & 98,5956 & 1,6433 & 6767,5164 & 6905,629 & 8124,2694 & 3,2339 & 5,4535 & 10,5962 \\
\hline 37,095 & 110 & 10,7754 & 98,5873 & 1,6431 & 7443,64632 & 7595,5575 & 8935,95 & 3,2337 & 5,4531 & 10,5953 \\
\hline 38,005 & 120 & 10,7745 & 98,5791 & 1,6430 & 8119,6632 & 8285,3706 & 9747,4948 & 3,2334 & 5,4526 & 10,5944 \\
\hline 39,215 & 130 & 10,7736 & 98,5709 & 1,6428 & 8795,56704 & 8975,0684 & 10558,904 & 3,2331 & 5,4521 & 10,5935 \\
\hline 40,559 & 140 & 10,7726 & 98,5617 & 1,6427 & 9471,26992 & 9664,5611 & 11370,072 & 3,2328 & 5,4516 & 10,5925 \\
\hline
\end{tabular}

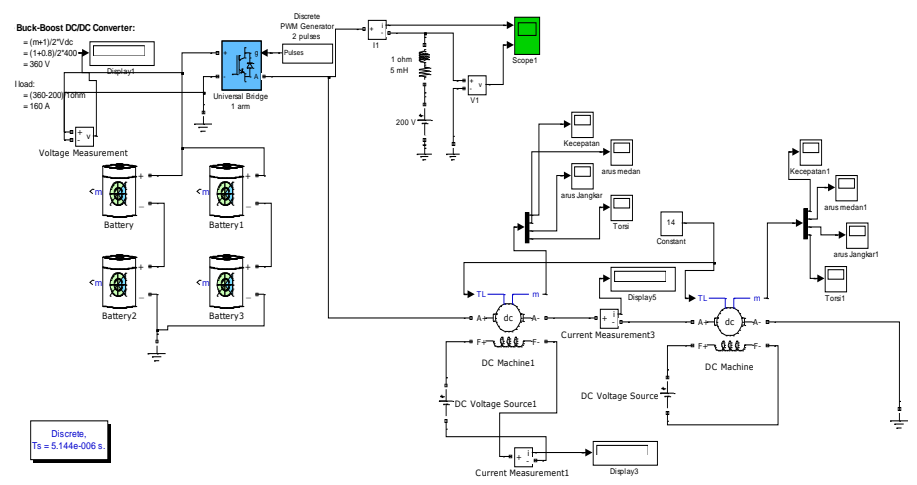

Figure. 9. Series circuit with converter in Matlab-simulink 
(pISSN: 2541-5972, eISSN: 2548-1479)

TABLE 5 .

SIMULATION RESULT OF PARALLEL CIRCUITS WHEN USAGE ON $10 \%$

\begin{tabular}{|c|c|c|c|c|c|c|c|c|c|c|}
\hline Q Motor & Torque & $\mathrm{rad} / \mathrm{s}$ & RPM & RPS & THP & SHP & BHP & Va & Vs $(\mathbf{m} / \mathbf{s})$ & Vs (knot) \\
\hline 26,788 & 0 & 13,788 & 126,1505 & 2,1025 & 0 & 0 & 0 & 4,1377 & 6,9776 & 13,5575 \\
\hline 27,7033 & 10 & 13,7871 & 126,1423 & 2,1024 & 865,8299 & 883,4999 & 1039,4116 & 4,1375 & 6,9772 & 13,5567 \\
\hline 28,5895 & 20 & 13,7862 & 126,134 & 2,1022 & 1731,5467 & 1766,8844 & 2078,6875 & 4,1372 & 6,9767 & 13,5558 \\
\hline 29,8399 & 30 & 13,7853 & 126,1258 & 2,1021 & 2597,1505 & 2650,1536 & 3117,8278 & 4,1369 & 6,9763 & 13,5549 \\
\hline 30,682 & 40 & 13,7844 & 126,1176 & 2,1020 & 3462,6413 & 3533,3074 & 4156,8323 & 4,1367 & 6,9758 & 13,5540 \\
\hline 31,6595 & so & 13,7835 & 126,1093 & 2,1018 & 4328,0190 & 4416,3459 & 5195,7011 & 4,1364 & 6,9754 & 13,5531 \\
\hline 32,5467 & 60 & 13,7826 & 126,1011 & 2,1017 & 5193,2837 & 5299,2691 & 6234,4342 & 4,1361 & 6,9749 & 13,5522 \\
\hline 33,4941 & 70 & 13,7817 & 126,0929 & 2,1015 & 6058,4353 & 6182,0769 & 7273,0316 & 4,1358 & 6,9744 & 13,5513 \\
\hline 34,3663 & 80 & 13,7808 & 126,0846 & 2,1014 & 6923,4739 & 7064,7693 & 8311,4933 & 4,1356 & 6,9740 & 13,5505 \\
\hline 35,2761 & 90 & 13,7799 & 126,0764 & 2,1013 & 7788,3995 & 7947,3464 & 9349,8193 & 4,1353 & 6,9735 & 13,5496 \\
\hline 36,1859 & 100 & 13,779 & 126,0682 & 2,1011 & 8653,2120 & 8829,8082 & 10388,0096 & 4,1350 & 6,9731 & 13,5487 \\
\hline 37,0957 & 110 & 13,7781 & 126,0599 & 2,1010 & 9517,9115 & 9712,1546 & 11426,0642 & 4,1348 & 6,9726 & 13,5478 \\
\hline 38,0055 & 120 & 13,7772 & 126,0517 & 2,1009 & 10382,4979 & 10594,3856 & 12463,9831 & 4,1345 & 6,9722 & 13,5469 \\
\hline 39,2153 & 130 & 13,7763 & 126,0435 & 2,1007 & 11246,9713 & 11476,5013 & 13501,7663 & 4,1342 & 6,9717 & 13,5460 \\
\hline 40,559 & 140 & 13,7754 & 126,0352 & 2,1006 & 12111,3317 & 12358,5017 & 14539,4138 & 4,1340 & 6,9713 & 13,5452 \\
\hline
\end{tabular}

Based on tabel 4 , the input data is carried out, at the time included $10 \%$ of the battery. From the calculation of the formula, it can be seen Vs or speed service on the series circuit. Like for example when the inputted torque variation 0 it will be produced BHP was $0 \mathrm{~kW}$ while the speed in $\mathrm{rad} / \mathrm{s}$ is 10.7854 and its speed Vs is 10.6051 knots. As for BHP produced by $11370.072140 \mathrm{KW}$ while the speed in $\mathrm{rad} / \mathrm{s}$ is 10.7726 and its speed Vs is 10.5925 knots. The series circuit with converter in Matlab-Simulink are presented on Figure 9.
Based on tabel 5, the input data is carried out, at the time included $10 \%$ of the battery. From the calculation of the formula, it can be seen Vs or speed boat service on a parallel circuit. Like for example when the inputted torque variation 0 it will be produced BHP was $0 \mathrm{~kW}$ while the speed in $\mathrm{rad} / \mathrm{s}$ is 13.788 and its speed Vs is 13.5575 knots. As for BHP produced by 14539.4138140 KW while the speed in $\mathrm{rad} / \mathrm{s}$ is 13.7754 and its speed Vs is 10.5452 knots. The parallel circuit with converter in Matlab-Simulink are presented on Figure 10.

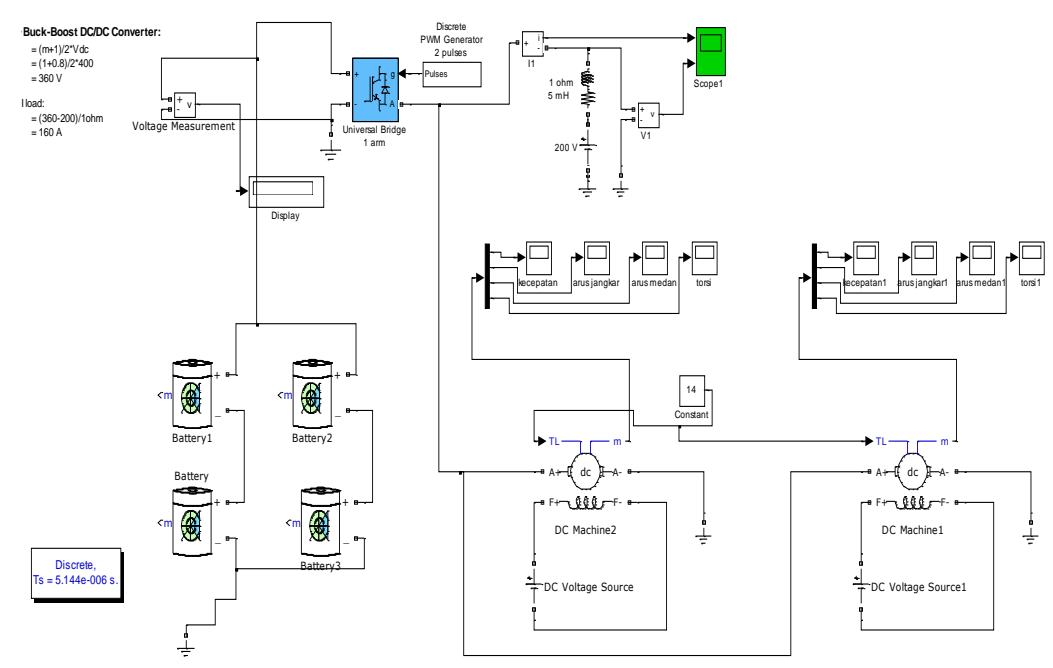


(pISSN: 2541-5972, eISSN: 2548-1479)

TABLE 6. SIMULATION RESULT OF SERIES CIRCUITS WITH CONVERTER

\begin{tabular}{|c|c|c|c|c|c|c|c|c|c|c|c|c|}
\hline $\begin{array}{c}\text { Capacity } \\
(\%)\end{array}$ & Q Motor & Torque & $\mathrm{rad} / \mathrm{s}$ & $\begin{array}{c}\text { Drop } \\
\text { voltage }\end{array}$ & RPM & RPS & THP & SHP & BHP & $\mathrm{Va}$ & $\begin{array}{c}\mathrm{Vs} \\
(\mathrm{m} / \mathrm{s})\end{array}$ & Vs (knot) \\
\hline $100 \%$ & 38,8 & 140 & 11,3325 & 222 & 103,6844 & 1,7281 & 9963,534 & 10166,87 & 11961,03 & 3,4008 & 5,7350 & 11,1431 \\
\hline $90 \%$ & 37,4 & 140 & 10,7892 & 205,8 & 98,7136 & 1,6452 & 9485,865 & 9679,454 & 11387,59 & 3,2378 & 5,4600 & 10,6089 \\
\hline $80 \%$ & 36 & 140 & 10,7798 & 205,6 & 98,6276 & 1,6438 & 9477,6 & 9671,021 & 11377,67 & 3,2350 & 5,4553 & 10,5996 \\
\hline $70 \%$ & 37,75 & 140 & 10,77 & 205,4 & 98,5379 & 1,6423 & 9468,984 & 9662,229 & 11367,33 & 3,2320 & 5,4503 & 10,5900 \\
\hline $60 \%$ & 33,2 & 140 & 10,757 & 205,1 & 98,4190 & 1,6403 & 9457,554 & 9650,566 & 11353,61 & 3,2281 & 5,4437 & 10,5772 \\
\hline $50 \%$ & 39,94 & 140 & 10,734 & 204,8 & 98,2085 & 1,6368 & 9437,333 & 9629,931 & 11329,33 & 3,2212 & 5,4321 & 10,5546 \\
\hline $40 \%$ & 40,188 & 140 & 10,7094 & 204,2 & 97,9835 & 1,6331 & 9415,704 & 9607,862 & 11303,37 & 3,2139 & 5,4197 & 10,5304 \\
\hline $30 \%$ & 33,2 & 140 & 10,664 & 203,3 & 97,5681 & 1,6261 & 9375,789 & 9567,131 & 11255,45 & 3,2002 & 5,3967 & 10,4858 \\
\hline $20 \%$ & 39,005 & 140 & 10,5709 & 201,6 & 96,7163 & 1,6119 & 9293,935 & 9483,607 & 11157,19 & 3,1723 & 5,3496 & 10,3942 \\
\hline $10 \%$ & 39,22 & 140 & 10,2885 & 196,2 & 94,1325 & 1,5689 & 9045,649 & 9230,254 & 10859,12 & 3,0875 & 5,2067 & 10,1165 \\
\hline
\end{tabular}

According to Table 6, to get data with a speed of 0 (error) then on the number of attempts to input the data included $0.539 \%$ on the battery. From the calculation of the formula, it can be seen Vs or speed boat service on the series circuit. Like for example when the inputted torque variation 0 it will be produced BHP was $0 \mathrm{~kW}$ while the speed in rad / $\mathrm{s}$ is 0.5334 and its speed Vs is 0.5245 knots. As for the variations in torque produced $140 \mathrm{BHP}$ at $548.9459 \mathrm{KW}$ while the speed in $\mathrm{rad} / \mathrm{s}$ is 0.5201 and its speed Vs is 0.5114 knots. At the time of full torque, the full capacity of its service speed is 11.1 knots. This proves if at the time of full torque condition then speeds between 10-11 knots for the series circuit.

\section{CONCLUSION}

Based on the result, the conclusion of this research are following:

1. The service speed of parallel circuit of the motor submerged vehicle is 14 knots and the speed of the condition of the vessel is in a state patrol as usual.

2. The service speed of series circuit of the motor submerged vehicle is 12 knots and the speed of the condition of the vessel is in a state patrol as usual.

3. Motor circuit in parallel with the converter services speed is 11 knots and the speed of the condition of the vessel is in a state patrol as usual.

4. Motor circuit in series with the converter services speed was 21.5 knots and at that speed condition of the vessel is in a state patrol as usual and this speed is the maximum speed.

\section{REFERENCES}

[1] Zuhal; [1991]; "Dasar Tenaga Listrik"; Penerbit ITB; Bandung.

[2] Berahim, Hamzah Ir.; [1991]; "Pengantar Teknik Tenaga Listrik"; Andi Offset; Yogyakarta.

[3] Tachibana, Y. dkk; [1985]; "Diesel Electric Propulsion System of Ice Breaker 'SHIRASE' "; Jurnal on Bulletin of The M.E.S.J. Vol. 13 No. 1; Jepang.

[4] Sarwito, Sardono Ir; [2006]; "Sistem Kelistrikan dan pengendalian"; ITS; Surabaya
[5] Burcher, Roy; [1994]; "Concepts in Submarine Design"; Cambridge University Press; England.

[6] Kitab Undang-Undang Hukum Dagang (KUHD) 1935.

[7] Undang-Undang RI No. 17 Tahun 2008 tentang Pelayaran.

[8] Safety of Life At Sea (1976) 
